\title{
ANALYSIS ON CAR COMMUTERS' BEHAVIOR DURING A MASSIVE DOWNPOUR BASED ON PROBE DATA AND QUESTIONNAIRE SURVEY
}

\author{
Mohammad Hannan Mahmud KHAN ${ }^{1}$, Motohiro FUJITA ${ }^{2}$ and \\ Wisinee WISETJINDAWAT ${ }^{3}$ \\ ${ }^{1}$ Student member of JSCE, Graduate Student, Dept. of Civil Eng., Nagoya Institute of Technology \\ (Gokiso, Showa, Nagoya 466-8555, Japan) \\ E-mail: cj113501@stn.nitech.ac.jp \\ ${ }^{2}$ Member of JSCE, Professor, Dept. of Civil Eng., Nagoya Institute of Technology \\ (Gokiso, Showa, Nagoya 466-8555, Japan) \\ E-mail: fujita.motohiro@nitech.ac.jp \\ ${ }^{3}$ Member of JSCE, Assistant Prof., Dept. of Civil Eng., Nagoya Institute of Technology \\ (Gokiso, Showa, Nagoya 466-8555, Japan) \\ E-mail: wisinee@nitech.ac.jp
}

\begin{abstract}
A massive downpour due to Typhoon Roke attacked the Tokai region on $20^{\text {th }}$ September, 2011. Several roads in the northeastern part of Nagoya city and the adjacent areas were closed to traffic, resulting in a serious commuter chaos. In this research, we attempted to explore the effects of departure hours, early or late departure, the significance of acquiring proper traffic information as well as the impacts of road closures on the level of difficulty of home returning trips. Regression models were developed using both questionnaire survey and taxi probe data. Questionnaire survey can gather drivers' information; however, it is difficult to gather the actual changes in travel condition. On the other hand, probe data can demonstrate a real time change in travel condition at every couple of minutes. Therefore, this study presents a combined usage of both data for a clearer explanation on the travel condition and the behavior of drivers during the typhoon. The findings revealed that the difficulty to gather reliable and comprehensive information on the traffic regulations enforced temporarily during the typhoon had led drivers facing the closure sections and the consequent very long travel delay. In fact, these delays can be avoided if the drivers had chosen the right detour route from the beginning. Based on the findings, this paper also suggests some proper countermeasures to reduce the severity of commuter chaos for the future disaster.
\end{abstract}

Key Words: downpour, transportation system failure, car user, traffic information, commuter chaos

\section{INTRODUCTION}

The damages due to typhoons had caused much economic losses to Japan, although the severity of an occurrence is much less than that of a large scale earthquake. This is because this type of disaster occurred rather frequently. As an example, the massive downpour due to Typhoon Roke which attacked the Tokai region from the afternoon until late evening of $20^{\text {th }}$ September 2011 caused a loss of more than 1 trillion Yen ${ }^{1)}$. During the event, several transportation services were closed. The inundations and the consequent road closures at several locations resulted in a very serious commuter chaos during home returning trips.

In this study, the data from a questionnaire survey which was conducted soon after Typhoon Roke as well as the probe data of taxis operating on the same day were used to analyze the impacts of the disaster on the returning home commuters.

Generally, it is difficult for a questionnaire survey to gather such detailed information as the changes in travel condition, congestion level, and road closures at every minute along the travel route. However, questionnaire survey can gather other drivers' information such as the differences on departure time, travel route, and travel time between on a regular day and on the day of typhoon. Also, the questionnaire survey can obtain the attribution of drivers, their habits, as well as their opinions regarding countermeasures to the disaster. On the other hand, although taxi probe data cannot provide such information; 
however, the data can demonstrate the real time changes in travel condition at every couple of seconds or minutes. Also, the data can be visualized on a GIS map.

Utilizing both information can complete each other drawbacks. However, there is only a few studies considering this approach. Therefore, this paper aims at providing an analysis using both questionnaire and probe data in order to obtain a better representation of the road situation and drivers' circumstances, and improve the quality of the analysis on the difficulty of returning home. We focus on the problem on stranded commuters during the 2011 Typhoon Roke in Tokai region. Based on both data sources, several regression models representing the difficulty to return home are developed. Furthermore, the effects of the acquisition of the information and countermeasures related to road closures on the returning home of stranded commuters during the heavy downpour are investigated.

\section{LITERATURE REVIEW}

In recent years, there are an increasing number of researches on commute changes due to disasters. Depending on the characteristics of disaster, the changes in commute patterns are rather different. Some disasters such as earthquakes and hurricanes can cause heavy damages to infrastructures. Often the damages are so severe and required a long period of time until the infrastructures can be operable again, and hence this situation results in a long period disruption on commuters' travel pattern. In the US, several works related to commute pattern changes after a hurricane or earthquake can be found. To name a few, Guiliano and Golob ${ }^{2)}$ studied the impacts on commuting behaviors after two major transport corridors were heavily damaged by the Northridge Earthquake. They found that automobile users preferred to shift route, travel schedules, and destination rather than to shift to public transport mode or share riding.

Commuter chaos occurred often even after a small scale incident. Especially after a major disaster, the adverse impacts due to the chaos can be enormous. After the 2011 Great East Japan Earthquake, in Tokyo alone, the disaster had caused more than 3 million commuters having trouble to return home ${ }^{3)}$. Hence, this problem drew much attention from many researchers to investigate further the problems regarding the commuter chaos after the earthquake. For example, Hiroi et al. ${ }^{4)}$ used a web-based survey to collect the information on home returning trips of people in Tokyo during the earthquake. A choice model was developed to explain the choice that the stranded commuters chose for returning home on the day of earthquake. Later, this model was used to estimate the number of populations who walked home on the day. Similarly, Fujiu et al. ${ }^{5}$ ) used a web-based survey to clarify the walking routes that the stranded commuters used in the aftermath of the same earthquake. They also investigated fire danger and available support facilities at different walking routes. Ito et al. ${ }^{6)}$ used a similar survey method and investigated further the availability of facilities and services for the people who walked home in the aftermath of the same earthquake. These studies provided an insight into the problems faced by the stranded commuters and their travel conditions in the aftermath of the 2011 Great East Japan Earthquake.

The impacts of the same disaster may be different in other regions considering the different geographic and transport facilities. Some works investigated the impacts of the earthquake to Tokai region. Koyama and $\mathrm{Okada}^{7)}$ conducted a questionnaire survey to companies in Nagoya regarding their workers' home returning behaviors by assuming public transport services were shut down after a large scale earthquake. The questionnaire asked the workers' behaviors both when receiving an earthquake warning and after the actual occurrence of the earthquake. The data was used to estimate the number of stranded commuters. They concluded that the current shelters and evacuation facilities are inadequate for the upcoming large scale earthquake in the region.

Different disaster causes different consequences. The damages by a downpour disaster also have unique characteristics. The damages can be temporary until the heavy rain stops and the floods are drained. Some works regarding the commuter chaos during a massive downpour can be found. Mitamura et al ${ }^{8)}$ examined the problems public transport users experienced when returning home during the Tokai torrential rain. They also developed a binary choice model whether or not to return home on the date, based on a Stated Preference data assuming the torrential rain happened again. One of the interesting findings was that the worse experience the commuter has, the less likely they will return home. Regarding the consequences of the torrential rain to automobile users, Sakamoto et $a .^{9)}$ analyzed the impacts of traffic information on drivers' decision whether to return home or to stay at workplace based on a data collected from a questionnaire survey. They found that if the travel time is 4-5 times of the usual travel time, $80 \%$ of the drivers' prefer to stay at office.

Most researches in this topic were conducted based on a questionnaire survey either telephone, internet, or paper based. With today technology, it is 
possible to analyze the impacts of disaster on travel behavior using GPS data from car navigation system. The precision of the GPS data is excellent, proven by the work by Liang et al. ${ }^{10)}$ which successfully used the GPS data from taxis to model the arterial speed. However, only very few studies used GPS data for studying traffic condition during a disaster. Khan et al. ${ }^{11)}$ was the first to demonstrate the potential of using a taxi probe data to study the traffic condition during home returning in a disaster situation. Although, the study showed a graphical representation of the traffic condition only during a torrential rain based on the GPS data of taxis operating during the disaster. Thus, there is still room for research on commuter behavior during disaster using GPS data.

\section{OVERVIEW OF THE DAMAGES DUE TO TYPHOON AND THE OUTLINE OF QUESTIONNAIRE SURVEY AND PROBE DATA}

\section{(1) The damages due to the 2011 Typhoon Roke}

In this section, the damages caused by the 2011 Typhoon Roke to Tokai region are briefly described. The typhoon originated in the south of Japan at 21:00 on $13^{\text {th }}$ September 2011 and gradually increased in strength. The precipitation was strong and continuous across Tokai region from the early evening of $19^{\text {th }}$ September until the evening of $21^{\text {st }}$ September. In particular, it rained heavily on $20^{\text {th }}$ September from Owari Tobu region which includes Nagoya and Kasugai cities, to Chuno and Tono regions which includes Tajimi city. Fig.1 shows the road closure sections as a result of heavy precipitation. The precipitation rate in the most severely affected areas in $20^{\text {th }}$ September is demonstrated in Fig.2.

During this typhoon, the precipitation in Tajimi during 10:00 and 16:00 was approximately 40-70 $\mathrm{mm} / \mathrm{h}$ (with the maximum of $73 \mathrm{~mm} / \mathrm{h}$ at 13:00). While in Nagoya, the hourly precipitation was about $40 \mathrm{~mm}$ during 13:00 and 15:00. However, after 17:00, the precipitation rate reduced to below 5-10 $\mathrm{mm} / \mathrm{h}$ in both regions.

The heaviest damages caused by flood happened at Moriyama ward. The damage covered an area of approximately $200 \mathrm{~m}$ from the left bank of Shonai River (depicted as A in Fig.3). This event occurred at 13:00 on $20^{\text {th }}$ September. The impact also went downstream to the area where Hatta, Jizo and Shonai Rivers joint together in Kasugai (depicted as B in Fig.3) and resulted in 378 homes flooded and 4,749 evacuees. Kōzōji station was also flooded with the height of $1 \mathrm{~m}$ during 12:00 - 15:00 on $20^{\text {th }}$ September.

F3 (Civil Engineering Informatics), Vol. 72, No. 2, I_1-I_13, 2016.

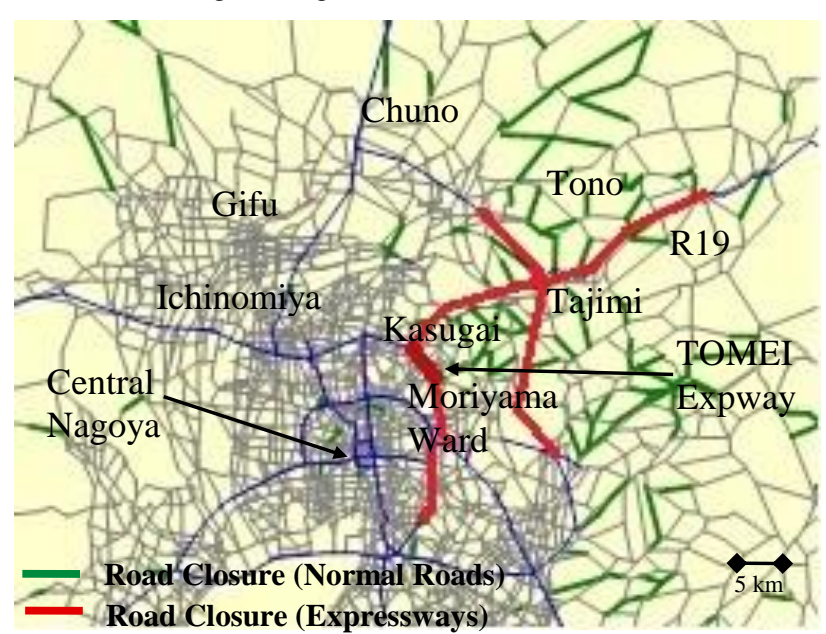

Fig.1 The road closure sections

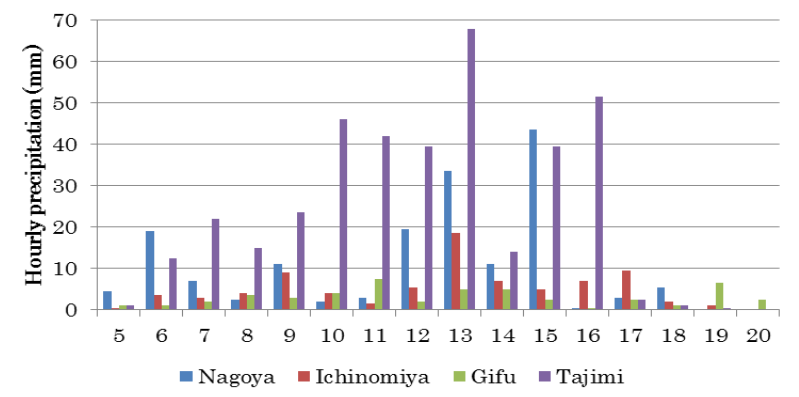

Fig.2 Precipitation at different locations

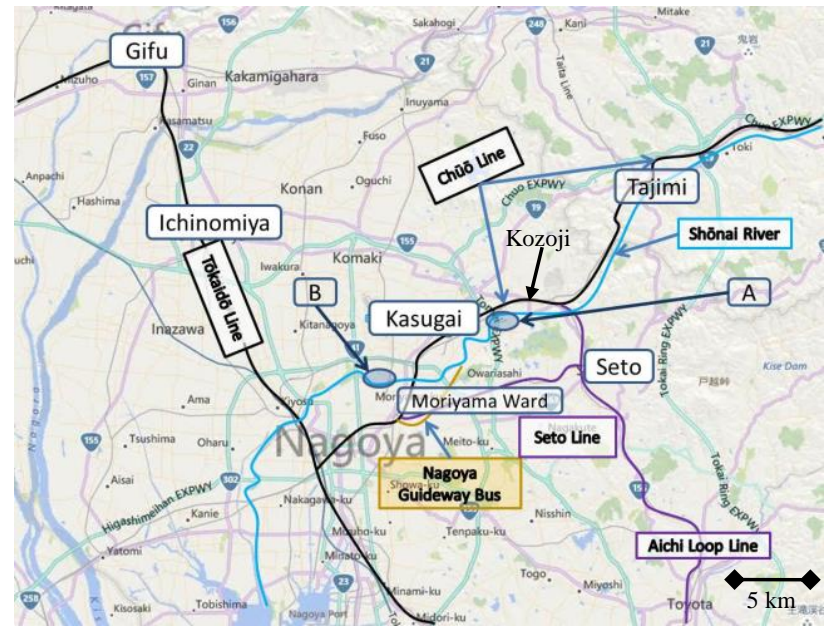

Fig.3 Location of main railway lines and stations for distributing the questionnaires

\section{(2) Traffic condition during the typhoon}

Fig.1 shows the sections of expressway and normal road in Tokai region which were closed due to the typhoon. From this figure, the main expressways in Tokai region were closed from 12:00 of $20^{\text {th }}$ September until $22^{\text {nd }}$ September. In addition, according to the prefectural homepage, approximately 140 locations along normal roads throughout Aichi and Gifu Prefectures were damaged. 159 locations in Nagoya and 75 locations in Kasugai were closed to traffic due to floods and landslides.

Next, Fig.3 shows the railway lines and stations 
considered in this study. Seto line, Meitetsu Nagoya main line, Aichi loop line (between Seto and Kozoji) were closed from the afternoon until 21:00 of $20^{\text {th }}$ September. JR Tokaido line, Chuo line was suspended from the afternoon of $20^{\text {th }}$ September until the following day. This suspension of the train services had caused a large number of stranded commuters. In addition, the congestion was very severe on the roads and also affected the bus services. However, the elevated guideway bus was not disrupted by the typhoon.

\section{(3) Outline of the Questionnaire Survey}

A questionnaire survey was conducted to commuters who either chose not to return home or used public transport, automobiles, or other forms of transportation to return home. The questionnaire survey, as outlined in Table 1, was distributed in the areas around the main stations of the JR Tokaido line and the JR Chuo line, which were suspended on $20^{\text {th }}$ September as shown in Fig.3. The areas locate along the guide way bus and major arterial roads (eg. Route 19) affected by road closures. The respondents returned the questionnaire by postal mail as well. This questionnaire asked the situations that stranded commuters faced and the returning home behaviors during the typhoon; the questions include the followings:

1) Commute mode, departure and arrival times, origin and destination, and type of accommodation, both on a regular day and on the day of typhoon.

2) The major intersection and road, expressway IC on the route to home during the massive downpour.

3) Information on the acquisition status regarding traffic regulations, including the timing, method of acquisition, and the accuracy of such information.

4) Personal attributes (e.g. sex, age, family composition, etc.)

Table 1 A brief outline of data collection during typhoon

\begin{tabular}{|c|c|c|c|c|}
\hline Locations & $\begin{array}{c}\text { Survey } \\
\text { Date }\end{array}$ & $\begin{array}{c}\text { Distributed } \\
\text { Number of } \\
\text { Question- } \\
\text { naires }\end{array}$ & $\begin{array}{c}\text { Number of } \\
\text { Returned } \\
\text { Question- } \\
\text { naires }\end{array}$ & $\begin{array}{c}\text { Re- } \\
\text { sponse } \\
\text { Rate } \\
(\%)\end{array}$ \\
\hline Ichinomiya-city & \multirow{6}{*}{$\begin{array}{c}2012 / \\
02 / 22 \\
\sim \\
2012 / \\
02 / 25\end{array}$} & 800 & 83 & 10.4 \\
\hline Gifu-city & & 800 & 83 & 10.4 \\
\hline Kasugai-city & & 800 & 109 & 13.6 \\
\hline Tajimi-city & & 1000 & 129 & 12.9 \\
\hline Seto-city & & 800 & 113 & 14.1 \\
\hline Moriyama-ward & & 800 & 117 & 14.6 \\
\hline
\end{tabular}

\section{(4) Outline of the Probe data}

The probe data used here is a GPS data of taxis operating in Aichi prefecture on the typhoon day, which was received from a Taxi Probe Research Center. These taxis were equipped with a device to transmit the position, time, speed, angle, and operating status, at every approximately $200 \mathrm{~m}$ or $20 \mathrm{sec}$. Since these taxis were also moving in the traffic stream on the typhoon day, the data can represent the congestion situation. The records of more than 650 taxi probe cars that travelled on $20^{\text {th }}$ September 2011 were used in the analysis among them only 24 taxi cars travelled between central Nagoya and Tajimi. Table 2 summarizes the number of probe vehicles during 16:00 to 17:00 on the above date in the entire Aichi prefecture and the Northeastern part of the region. Fig.4 demonstrates the total time required to travel from the center of Nagoya to different destinations in the Northeastern area at different departure times on the typhoon day.

Fig.5 shows the plot of probe vehicles on a GIS map for all taxis bound for Kasugai and Tajimi, towards the northeast direction from Nagoya on $20^{\text {th }}$ September from 11:00 until 24:00. In this figure, every vehicle with the speed of less than $2 \mathrm{~km} / \mathrm{h}$ is depicted in a large deep red circle, the speed of 2-4 $\mathrm{km} / \mathrm{h}$ is shown in a smaller and lighter red circle. The plots are different by the size and color for the respective speed class. A - D depict the congested sections on major roads due to road closures based on our analysis. A brief explanation of the areas and the situation on the typhoon day is described.

Section A: This section of Route 19 passes through several tunnels in mountainous area. Traffic volume of this section is about 40,000 veh/day. This road is primarily used for drivers traveling from Nagoya to Tajimi. On the typhoon day, this section was closed to traffic because of the landslide from 14:15 until the next day. However, far before this section, there is a two-lane road (both ways) with a narrow sideway merged into this section. Many cars heading for Tajimi avoided the closure sections and moved slowly using this sideway and thus resulted in a heavy traffic jam in this section.

Section B: This section is part of the road along the valley bound for Tajimi from Nagoya. This two-lane (both ways) road has no sideway and only a few traffic signals. This road was closed from 9:30 for the entire day in $20^{\text {th }}$ September due to the fear of landslide.

Section C: This section is closed at the Kasugai IC of Tomei expressway, which connects to Route 19. During the typhoon, the expressway section between Kasugai IC and Nagoya IC was closed to traffic from 15:00 until 21:00 on the same day. 
Table 2 Probe data during 16:00 to 17:00 on $20^{\text {th }}$ September

\begin{tabular}{|c|c|c|}
\hline Number of data & $\begin{array}{c}\text { Overall } \\
\text { area }\end{array}$ & $\begin{array}{c}\text { Northeastern } \\
\text { Area }\end{array}$ \\
\hline Total number of taxis & 465 & 186 \\
\hline Total number of trips & 607 & 203 \\
\hline Total number of probe locations & 9748 & 3017 \\
\hline
\end{tabular}

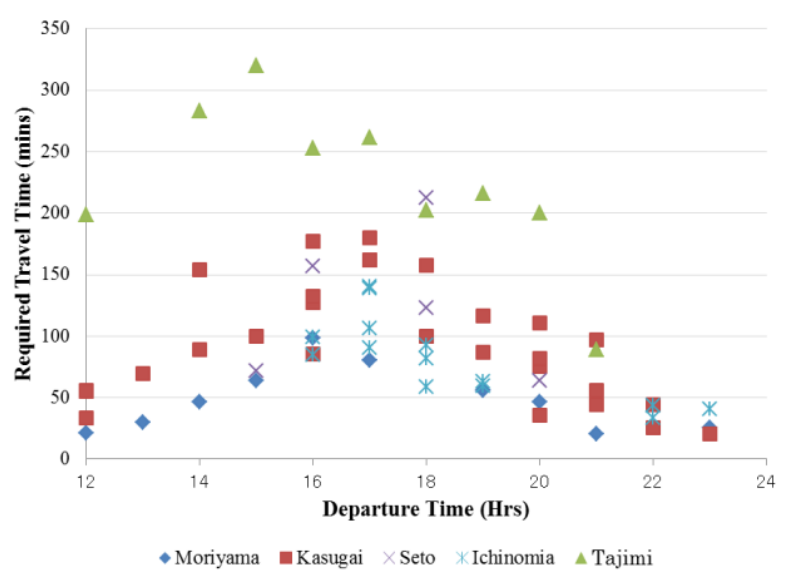

Fig.4 Travel time to different destinations at different departure times on the typhoon day based on the taxi probe data.

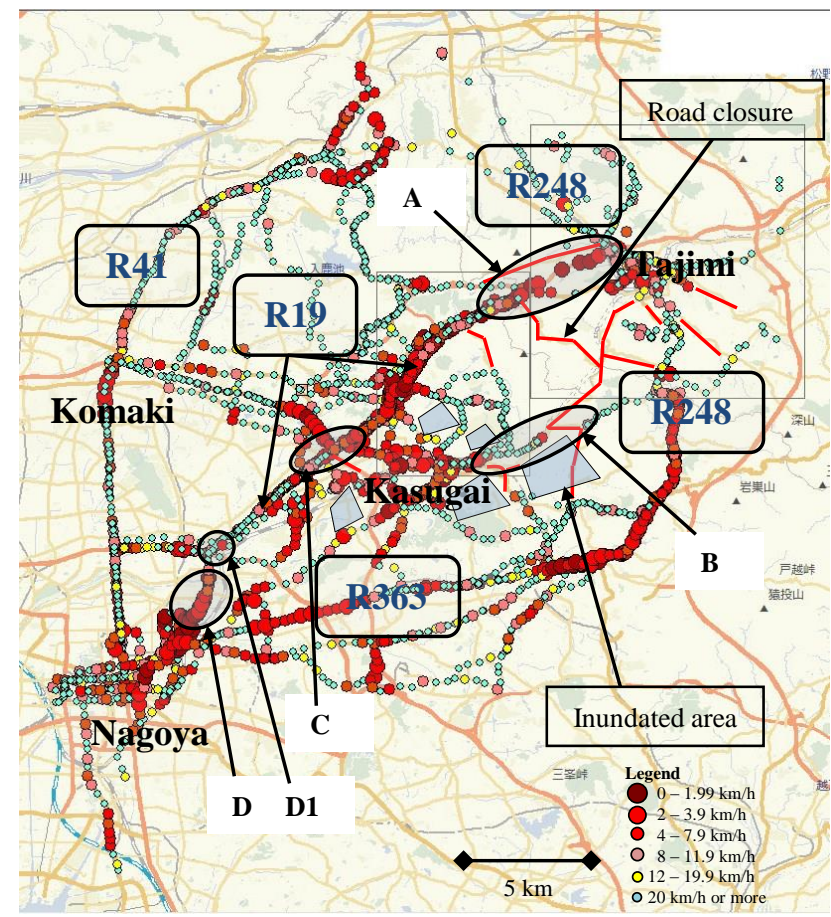

Fig.5 The congestion situation of the day of typhoon

Section D: This portion of Route 19 includes two bridges cross over Yada and Shonai rivers. Each direction of this road has 4 lanes with a daily traffic volume of about 50,000 veh/day. This area was inundated due to water upsurge, as stated in the previous section, resulting in the underpass and the dike road entering to Route 19 being closed. At Point D1, only one lane above the underpass is passable through the intersection between Routes 302 and 19.
Journal of Japan Society of Civil Engineers, Ser.

F3 (Civil Engineering Informatics), Vol. 72, No. 2, I_1-I_13, 2016.

\section{RETURNING HOME BEHAVIOR BY CAR DURING THE TYPHOON FROM QUESTIONNAIRE}

\section{(1) Overview}

In this section, we analyze the returning home behavior by car based on the questionnaire survey. 210 respondents who either used car or taxi to return home from their offices or schools during the typhoon, travelled for more than $20 \mathrm{~min}$, and provided all important attribution are used in the analysis. Here, we chose 20-min travel time as a threshold for the data selected for the analysis because the respondents would sufficiently feel the impacts of the disaster. Among the total 210 respondents who used car for returning home during the typhoon, 185 respondents used car on a regular basis, 40 respondents regularly used train as a commute mode but changed to taxi or car during the typhoon. About $5 \%$ of commuters who regularly used car decided not to return home and stayed at offices or schools on the typhoon day ( 7 respondents stayed at friend's houses, 2 respondents stayed in their cars, and 1 respondent stayed at a hotel). The attribution of the 210 samples include age (teens: $1 \%$, twenties: $6 \%$, thirties: $27 \%$, forties: $29 \%$, and fifties and more: $19 \%$ ), sex (male: 69\% and female: 31\%), and family composition (having small children: $25 \%$ and elderly: $10 \%)$.

\section{(2) Travel time during the typhoon}

Fig.6 compares the travel time required to return home between on a regular day and on the day of typhoon. On a regular basis, the maximum travel time was $2 \mathrm{~h}$ and the average travel time of all samples was about $60 \mathrm{~min}$; while on the day of typhoon, the maximum and the average values became $8 \mathrm{~h}$ and 4 h, respectively. Fig.7 demonstrates the scatterplot of the departure time and travel time required to return home during the disaster to the northeastern area, including Kasugai and Tajimi. The departure time between 14:00 and 18:00 required especially very long time to travel due to road closures and traffic regulations. Since the precipitation became lower after 19:00 from Fig.2, consequently the maximum travel time was shorter from $3 \mathrm{~h}$ to the normal travel time of $1 \mathrm{~h}$.

Fig.8 shows the relationship between the average travel speed to return home on the day of typhoon and the travel distance on a regular day. The speed related to the distance varies greatly due to the differences in the departure time, the effects of road closure and so on. 


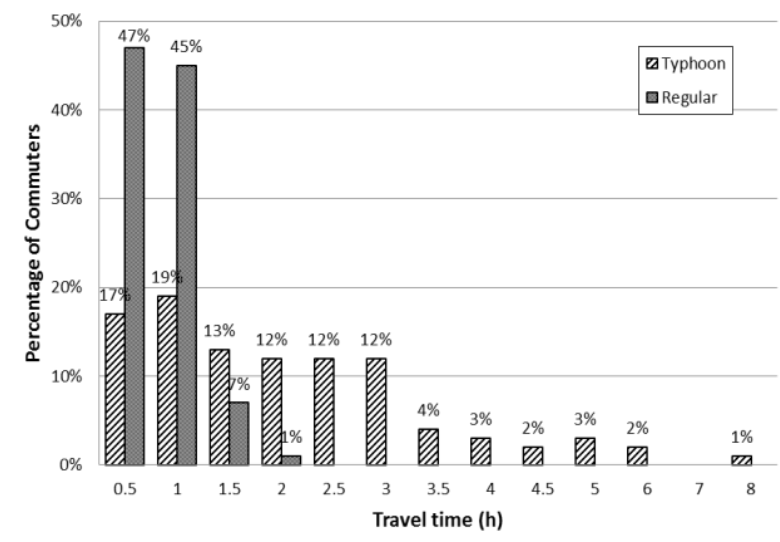

Fig.6 Variation in travel times between on a regular day and during the typhoon

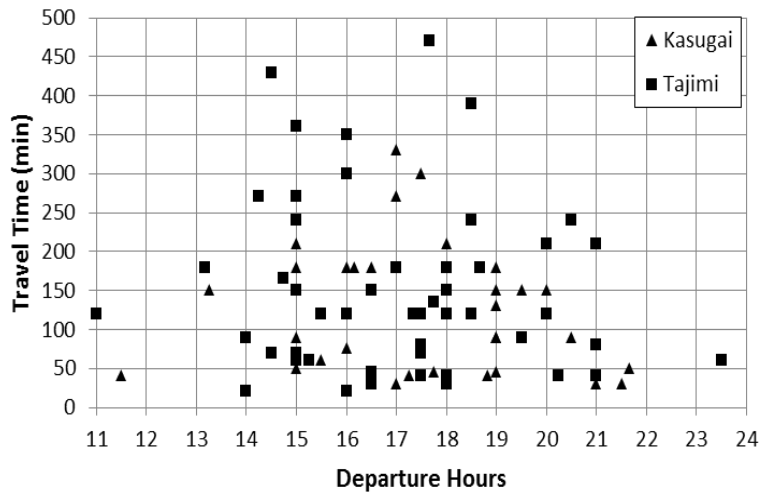

Fig.7 Travel time required for Northeastern area from Nagoya

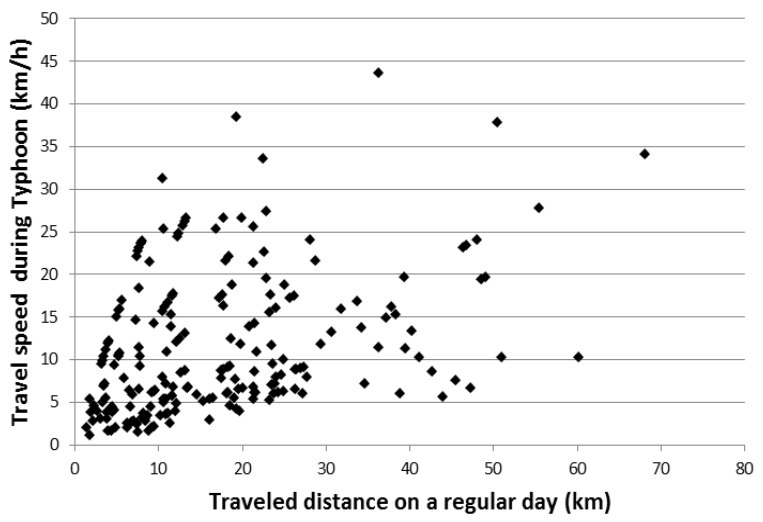

Fig.8 Average travel speed on the day of typhoon and travel distance on a regular day

\section{(3) Acquisition of traffic information during the typhoon}

Here, the methods that the drivers used to obtain the traffic information on the typhoon day are described. Fig.9 shows the acquisition status of the respondents to gather the traffic regulations before departure. $49 \%$ of the respondents was able to gather the information before departure, while the remaining were either unable to gather the information or did not attempt to do so.
Journal of Japan Society of Civil Engineers, Ser.

F3 (Civil Engineering Informatics), Vol. 72, No. 2, I_1-I_13, 2016.

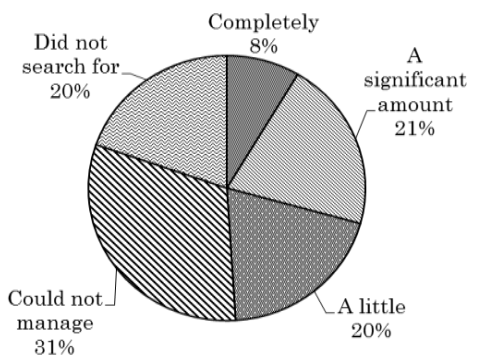

Fig.9 Acquisition of traffic information before departure

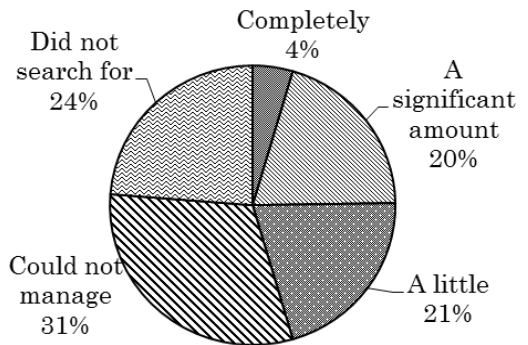

Fig.10 Acquisition of traffic information on the way during traveling

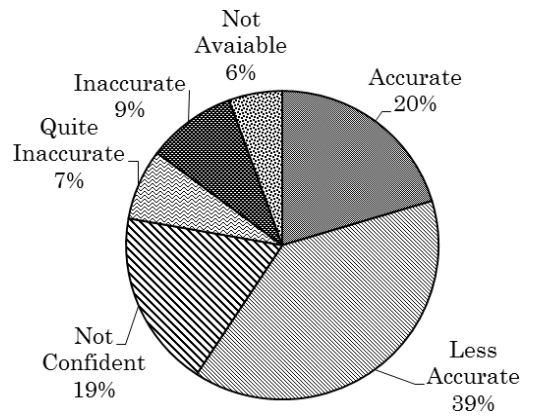

Fig.11 The accuracy of the gathered information

Fig.10 shows the respondents who gathered the information on the way during traveling. 55\% of respondents could not gather the information. In other words, the respondents who were able to gather the information were less than half. Fig.11 depicts the accuracy of the traffic information that the respondents received. 59\% of the respondents said that the information was accurate. However, $16 \%$ of responses indicated that the received information was inaccurate and $19 \%$ of respondents were not confident. Some additional comments from the respondents are, for example, inaccurate traffic information were received from the beginning till the end during the disaster, a wrong decision was made due to receiving wrong information initially but the information was corrected in the end.

\section{FLUCTUATION IN TRAFFIC DEMAND DURING TYPHOON}

\section{(1) Hourly fluctuation in traffic volume}

During the typhoon, many drivers departed at a different time from usual. In this section, the fluctu- 
ation in traffic volume as a result of the changes in departure time on the day of typhoon is presented.

Table 3 shows the average departure time on a regular day and on the day of typhoon comparing between male and female. On a regular day, the departure time of female commuters is an hour earlier than male. On the day of disaster, both male and female commuters departed an hour earlier than their usual departure time.

Fig.12 shows the differences of the departure time on the typhoon day and the usual departure time. The value in $\mathrm{x}$-axis is zero when the departure time on the typhoon day was as same as usual. Hence, the negative value is when the departure time was earlier than usual on the day of disaster and the positive value is the opposite. This figure demonstrates that commuters who generally departed late tend to depart earlier on the typhoon day. In case of departing later than usual on the day of typhoon, the departure time was within 2-3 $\mathrm{h}$ regardless of the departure time on a regular day.

Table 3 The average departure time on a regular day and on the day of Typhoon

\begin{tabular}{|c|c|c|}
\hline Sex & $\begin{array}{c}\text { Average departure time on } \\
\text { a regular day }\end{array}$ & $\begin{array}{c}\text { Average departure time } \\
\text { on the day of typhoon }\end{array}$ \\
\hline Male & $18: 47$ & $17: 35$ \\
\hline Female & $17: 10$ & $16: 20$ \\
\hline
\end{tabular}

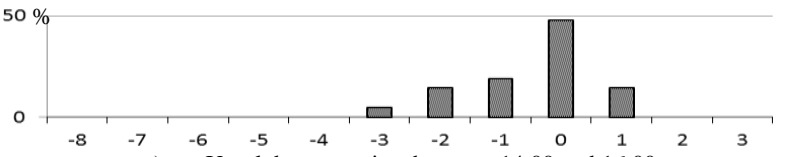
$50 \% \quad$ a) Usual departure time between 14:00 and 16:00
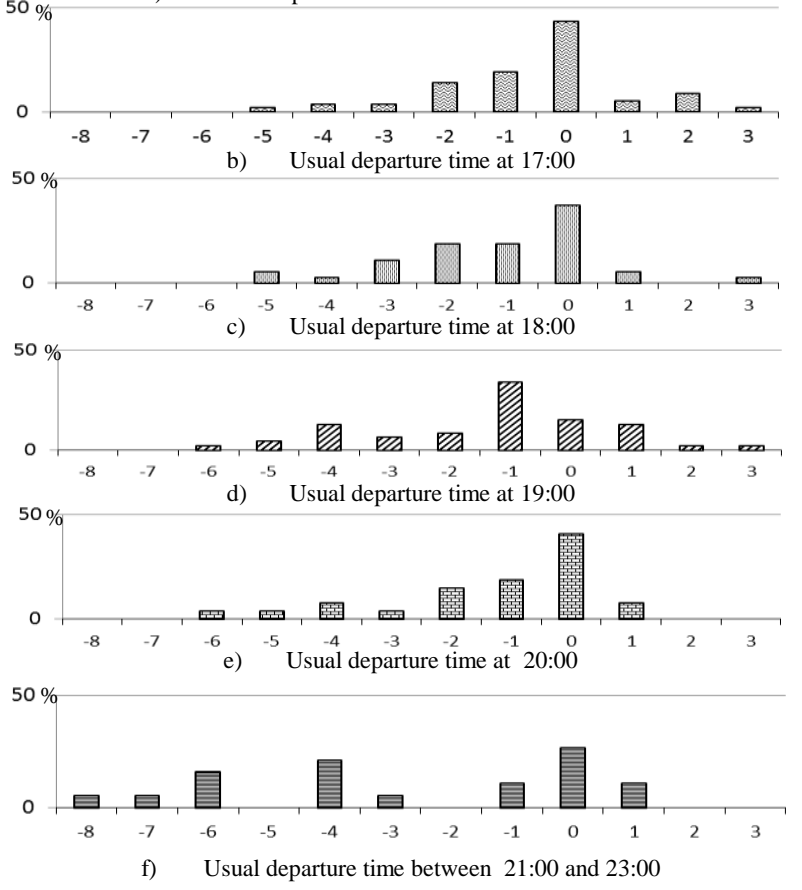

Fig.12 Variation in percentage of differences in hours for different departure time on a regular day

Also, regardless of the usual departure time, commuters started to depart approximately from 14:00 when the initial information on the flood damage was reported. The numbers increased gradually from the time of occurrence of the disaster until the regular departure time, and decreased about $2 \mathrm{~h}$ later than their regular time.

\section{QUANTITATIVE ANALYSIS OF THE DIFFICULTIES DURING TRAVELING UNDER THE TYPHOON}

Considering the average travel speed for different travel distance in Fig.8, we found that the degree of congestion and the impact of road closures to each person were quite different. Therefore, in this section, the travel time and the average travel speed are analyzed as dependent variables in regression analysis in order to find the factors influenced to the degree of difficulty to return home during the disaster.

The variables used in this analysis are as shown in Table 4. The 210 samples described in Section 4(1) are used in the analysis. After multiple attempts, Table 5 shows the best models in which only the significant parameters are remained. At first, we developed basic regression models for two types of dependent variables, including travel time and average travel speed. In both basic models of travel time and average travel speed, the significant parameters were similar. Although, the signs are different but they can be interpreted in the same way because these dependent variables have a high correlation coefficient with negative sign. Since the accuracy of the average travel speed model $\left(\mathrm{R}^{2}=0.59\right)$ is better than that of the travel time model $\left(\mathrm{R}^{2}=0.47\right)$, we selected to present only the average speed model for the analysis of the difficulty returning home during the typhoon. The basic average travel speed model is shown as Model 1 in Table 5.

Considering Model 1, we found that the travel speed increased when commuters travelled in a longer distance. This is because drivers made a long detour using uncongested sections in order to avoid the congestion. However, the speed fell if the travel distance on normal roads (without using an expressway) is long.

Considering the dummy variables of different departure time, we found that the travel speed was rather high when departed at 11:00 because the traffic volume was still very low and there were only a few road closure sections, although the precipitation became severe. For the departure variables between 14:00 and 16:00, the travel speed dropped largely 
due to the closures of Route 19 and some expressway sections. However, when departing after 21:00, the traffic volume decreased and hence the travel speed was increased. For the dummy variables of destination, drivers traveled to the northern direction from Nagoya (such as Ichinomiya, Gifu, etc.) were unaffected by the road closures and hence the travel speed was higher. The travel to Seto was not also very slow; although there was traffic congestion in the region, but drivers still had several alternative roads.

The Kasugai IC dummy indicates that drivers, who exited the expressway at this interchange, faced very severe traffic congestion. This might because of the closure of the expressway from Kasugai IC to the southern direction. The details are to be investigated in the next section.

\section{(2) Families with elderly and irregular car users}

In Model 1, there are also two dummy variables indicating having an elderly at home and the commuter is an irregular car user. The latter denotes the case when a regular public transport user chose to travel by taxi or use a company car to return home on the day of typhoon. These variables are significant and have no strong collinearity with other variables.

Considering the elderly dummy, the travel speed was rather slow, indicating that these commuters were facing severe traffic congestion. Some respondents stated that having elderly in the family caused them to return home under any circumstance in order to care the elderly from an anticipated danger due to the disaster. Thus, finding a neighbor to take care of the elderly when the commuter cannot return home might be a possible countermeasure. Next, the irregular drivers also travelled at a very low speed because they were not used to the driving circumstance.

\section{(3) Early or late departure}

In Model 2, three more dummy variables were added; they are 1) Earlier departure of $3 \mathrm{~h}$ or more than usual, 2) Later departure of $1 \mathrm{~h}$ or more than usual, and 3) Female dummy. These variables have collinearity with the departure time variables. As a result, only the dummy of departure at 11:00 was included in the model. Other variables are similar to Model 1. As discussed in the previous section, many commuters departed earlier than usual during the disaster. However, the sign of early departure is negative and can be interpreted that commuters who departed early travelled at a very low speed and required a long travel time. In contrary, people who departed late travelled faster and had a comparative less difficulty during the trips. The female dummy is also negative, indicating returning home trips of female required a long travel time; as discussed previously, female was more likely to depart early and encountered severe traffic congestion.

\section{(4) The accuracy of traffic information}

In this survey, there were also some questions regarding when the commuters gathered the information on traffic regulation and whether or not such information was accurate.

Table 4 Definition of Variables

\begin{tabular}{|c|c|}
\hline Variables & Definition \\
\hline Travel time & $\begin{array}{l}\text { The time required to travel on the day of } \\
\text { typhoon by the respondent (min) }\end{array}$ \\
\hline Average travel speed & $\begin{array}{l}\text { The ratio of travel distance below to the } \\
\text { travel time }(\mathrm{km} / \mathrm{h})\end{array}$ \\
\hline Travel distance & $\begin{array}{l}\text { Travel distance between origin and desti- } \\
\text { nation estimated by the questionnaire }(\mathrm{m})\end{array}$ \\
\hline $\begin{array}{c}\text { Travel distance } \\
\text { without Expressway }\end{array}$ & $\begin{array}{l}\text { Travel distance for respondent did not use } \\
\text { any expressway }(\mathrm{m})\end{array}$ \\
\hline Kasugai IC & $\begin{array}{l}\text { Dummy variable }=1 \text { : If respondent passed } \\
\text { the area around Kasugai IC, } 0 \text { : otherwise }\end{array}$ \\
\hline Irregular Car user & $\begin{array}{c}\text { Dummy variable=1: If respondent did not } \\
\text { commute by car on a regular day but used a } \\
\text { car on the day of typhoon, } 0 \text { : otherwise }\end{array}$ \\
\hline With Elderly & $\begin{array}{c}\text { Dummy variable }=1 \text { : if respondent's family } \\
\text { has elderly, } 0: \text { otherwise }\end{array}$ \\
\hline Female & Dummy variable $=1:$ Female, $0:$ otherwise \\
\hline Early Departure & $\begin{array}{c}\text { Dummy variable }=1 \text { : If respondent made an } \\
\text { early departure of } 3 \mathrm{~h} \text { or more on the day of } \\
\text { typhoon than usual, } 0 \text { : otherwise }\end{array}$ \\
\hline Late Departure & $\begin{array}{c}\text { Dummy variable }=1 \text { : If respondent made } \\
\text { delayed departure of } 1 \mathrm{~h} \text { or more on the day } \\
\text { of typhoon than usual, } 0 \text { : otherwise }\end{array}$ \\
\hline Route 22,21 and 41 & $\begin{array}{l}\text { Dummy variable }=1 \text { : If respondent used } \\
\text { Routes } 21 \text { and } 41 \text {, or } 22,0 \text { : otherwise }\end{array}$ \\
\hline $\begin{array}{l}\text { Distance with Traffic } \\
\text { information }\end{array}$ & $\begin{array}{l}\text { Dummy variable=Travel distance (the } \\
\text { same value as the above Travel distance } \\
\text { variable): If respondent get traffic infor- } \\
\text { mation before departure, } 0 \text { : otherwise }\end{array}$ \\
\hline $\begin{array}{l}\text { Distance without } \\
\text { Traffic information }\end{array}$ & $\begin{array}{l}\text { Dummy variable=Travel distance (the } \\
\text { same value as the above Travel distance } \\
\text { variable): If respondent did not get traffic } \\
\text { information before departure, 0: otherwise }\end{array}$ \\
\hline $\begin{array}{l}\text { Inaccurate infor- } \\
\text { mation }\end{array}$ & $\begin{array}{l}\text { Dummy variable=1: If the traffic infor- } \\
\text { mation that respondent received was in- } \\
\text { accurate, } 0 \text { : otherwise }\end{array}$ \\
\hline $\begin{array}{l}\text { Departure 11:00 to } \\
\text { 23:00 }\end{array}$ & $\begin{array}{c}\text { Dummy variable }=1 \text { : If respondent departed } \\
\text { at 11:00 until 23:00, 0: otherwise }\end{array}$ \\
\hline $\begin{array}{l}\text { Destination Ichino- } \\
\text { miya, Gifu, Seto or } \\
\text { Kasugai }\end{array}$ & $\begin{array}{c}\text { Dummy variable=1: If respondent's des- } \\
\text { tination was Ichinomiya, Gifu, Seto or } \\
\text { Kasugai, 0: otherwise }\end{array}$ \\
\hline
\end{tabular}


Table 5 Average Travel Speed model

\begin{tabular}{|c|c|c|c|c|c|c|}
\hline \multirow{2}{*}{ Explanatory Variables } & \multicolumn{2}{|c|}{ Model 1 } & \multicolumn{2}{|c|}{ Model 2} & \multicolumn{2}{|c|}{ Model 3} \\
\hline & Estimate & t-stat & Estimate & t-stat & Estimate & t-stat \\
\hline Intercept & 6.549 & $8.27 * * *$ & 6.444 & $6.51 * * *$ & 13.73 & $7.38 * * *$ \\
\hline Travel distance & 0.000414 & $6.15 * * *$ & 0.000431 & $5.51 * * *$ & - & - \\
\hline $\begin{array}{c}\text { Travel distance without } \\
\text { Expressway }\end{array}$ & -0.000212 & $-2.96 * * *$ & -0.000242 & $-2.94 * * *$ & -0.00023 & $-2.28 * *$ \\
\hline Kasugai IC & -6.346 & $-1.9^{*}$ & -6.618 & $-1.72 *$ & - & - \\
\hline Irregular car users & -2.798 & $-2.7 * * *$ & -2.844 & $-2.31 * *$ & - & - \\
\hline With elderly & -2.322 & $-1.82^{*}$ & - & - & - & - \\
\hline Female & - & - & -1.817 & $-1.86^{*}$ & - & - \\
\hline Early Departure & - & - & -2.27 & $-1.92 *$ & - & - \\
\hline Late Departure & - & - & 2.52 & $1.84 *$ & - & - \\
\hline Routes 21 and 41 & - & - & - & - & -9.907 & $-3.21 * * *$ \\
\hline Route 22 & - & - & - & - & 7.172 & $2.22 * *$ \\
\hline $\begin{array}{c}\text { Distance with Traffic } \\
\text { information } \\
\end{array}$ & - & - & - & - & 0.000336 & $3.47 * * *$ \\
\hline $\begin{array}{c}\text { Distance without traffic } \\
\text { information }\end{array}$ & - & - & - & - & 0.000325 & $3.4 * * *$ \\
\hline Inaccurate information & - & - & - & - & -4.725 & $-1.89 *$ \\
\hline Departure_11:00 & 14.624 & $3.73 * * *$ & 18.364 & $4.00 * * *$ & - & - \\
\hline Departure_14:00 & -4.077 & $-2.54 * *$ & - & - & -12.227 & $-3.16^{* * *}$ \\
\hline Departure_15:00 & -3.989 & $-3.24 * * *$ & - & - & -8.998 & $-3.29 * * *$ \\
\hline Departure_16:00 & -3.649 & $-3.38 * * *$ & - & - & - & - \\
\hline Departure_21:00 & 10.802 & $5.08 * * *$ & - & - & - & - \\
\hline Departure_22:00 & 11.602 & $4.66 * * *$ & - & - & - & - \\
\hline Departure_23:00 & 12.701 & $3.26 * * *$ & 10.541 & $2.35^{* *}$ & - & - \\
\hline Destination_Ichinomiya & 6.289 & $4.92 * * *$ & 6.379 & $4.26 * * *$ & - & - \\
\hline Destination_Gifu & 9.923 & $6.55 * * *$ & 11.365 & $6.62 * * *$ & - & - \\
\hline Destination_Seto & 4.906 & $4.6 * * *$ & 4.585 & $3.71 * * *$ & - & - \\
\hline Destination_Kasugai & - & - & - & - & -7.112 & $-2.43 * *$ \\
\hline Number of Samples & \multicolumn{2}{|c|}{207} & \multicolumn{2}{|c|}{206} & \multicolumn{2}{|c|}{54} \\
\hline R Square & \multicolumn{2}{|c|}{0.592} & \multicolumn{2}{|c|}{0.447} & \multicolumn{2}{|c|}{0.564} \\
\hline
\end{tabular}

Note: $* * * * * *$ indicate that the variables are significant at $1 \%$ significance level, $5 \%$ significance level, and $10 \%$ significance level, respectively.

However, only a few number of respondents answered these questions. Thus, 54 samples can be used in the analysis on the impact of the accuracy of the provided traffic information on travel speed; the results are presented in Model 3.

The dummy variable of Routes 21 and 41 became significant and is negative. The dummy variable for Route 22 is also significant and is positive. This can be explained that Route 22 is an arterial road from Nagoya to the northern region and drivers could drive rather fast and there was no road closure on the road on the typhoon date. Whereas, Routes 21 and 41 are negative which indicate severe traffic congestion occurred. This was because a large number of cars travelled to Tajimi avoided the closure of Route 19 by using these roads.

From the variables of Distance with and without traffic information, the respondents who gathered the information before departure travelled faster than ones who did not. However, considering the variable of the inaccurate information, the travel speed dropped by $4.7 \mathrm{~km} / \mathrm{h}$ when the received information was inaccurate. Thus, the consequence of acquiring inaccurate information is not small.

\section{REGIONAL IMPACTS DUE TO ROAD CLOSURES BASED ON TAXI PROBE DATA}

Here, we further analyze the traffic condition, focusing on Tajimi, which is a city situated $30 \mathrm{~km}$ from the central Nagoya. Based on the taxi probe data, Fig.13 shows three major routes towards Tajimi from Central Nagoya (Routes A, B, and C). Route A shows the trajectory of a taxi probe which used Route 19 at the beginning. From Point X, due to the road closure, the taxi took a detour route using the sideway in mountains area to travel to Tajimi as described in Section 3(4). The plots of probe cars around Tajimi city showed some discontinuities. This might be due to transmission errors in mountainous terrain and deep forest. For Route B, the taxi travelled using the road on the south of Route 19, turned left to Route 248, and entered to Tajimi from the south. For Route C, the taxi traveled to the north direction, turned right to Route 248 , and entered to Tajimi from the north. If using Routes B or C from the beginning, drivers would not encounter the severe traffic congestion. 


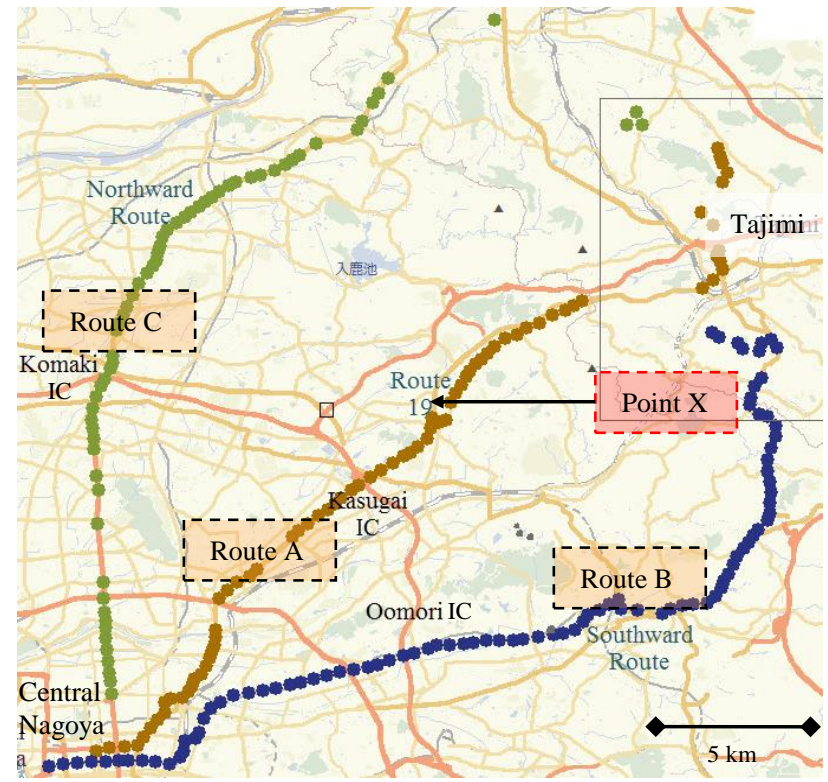

Fig.13 Taxis' travelled routes to Tajimi on the day of typhoon.

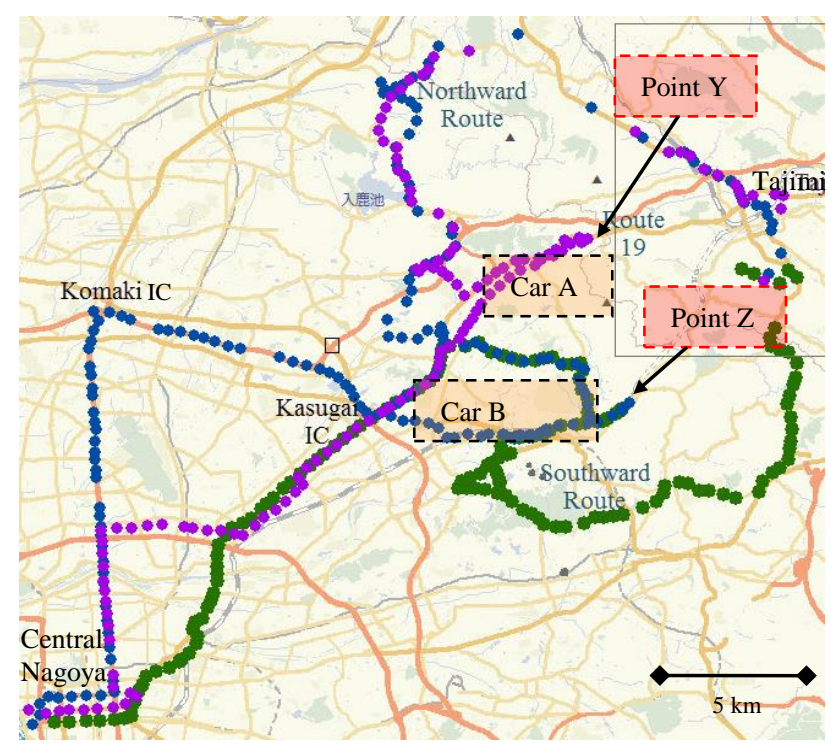

Fig.14 Taxis' travelled routes to Tajimi on the day of typhoon with more difficulties.

Fig.14 demonstrates three routes that taxis which faced very severe traffic congestion travelled on the day. Since a U-turn control was enforced at the closure on Route 19 (Point Y), Car A on this route had to make a very long round trip of about $4 \mathrm{~km}$ in front of the closure point. Car B also made a U-turn in front of the closure Point $\mathrm{Z}$ along the valley line of the Nagoya-Tajimi road. The driver travelled back and forth at the approximately $3 \mathrm{~km}$ section.

In the data, there were 24 probe cars traveled from Central Nagoya to Tajimi. The travel trajectories were analyzed using regression technique in which the travel time is the dependent variable. Table 6 shows the variables used in the analysis. The regression models for travel time on the day of typhoon from the probe data are presented in Table 7.
Journal of Japan Society of Civil Engineers, Ser. F3 (Civil Engineering Informatics), Vol. 72, No. 2, I_1-I_13, 2016.

Table 6 Variable definitions for Travel Time Model

\begin{tabular}{|c|c|}
\hline Variables & Definition \\
\hline Travel Time & $\begin{array}{c}\text { The time required for the taxi probe to } \\
\text { travel from Nagoya to Tajimi (mins) }\end{array}$ \\
\hline U-turn & $\begin{array}{c}\text { Dummy variable=1: If took U-turn during } \\
\text { the trip, 0: otherwise }\end{array}$ \\
\hline $\begin{array}{c}\text { Time before Initial } \\
\text { detour }\end{array}$ & $\begin{array}{c}\text { The duration that the taxi probe spent } \\
\text { before its first attempt to detour (mins) }\end{array}$ \\
\hline Passing Kasugai IC & $\begin{array}{c}\text { Dummy variable=1: If passed the area } \\
\text { around Kasugai IC, 0: otherwise }\end{array}$ \\
\hline Number of detours & The number of detours during the trip \\
\hline $\begin{array}{c}\text { Expressway till } \\
\text { Komaki }\end{array}$ & $\begin{array}{c}\text { Dummy variable=1: If used expressway till } \\
\text { Komaki, 0: otherwise }\end{array}$ \\
\hline $\begin{array}{c}\text { Expressway till } \\
\text { Oomori }\end{array}$ & $\begin{array}{c}\text { Dummy variable=1: If used expressway till } \\
\text { Oomori, 0: otherwise }\end{array}$ \\
\hline Departure_21:00 & $\begin{array}{c}\text { Dummy variable=1: If departure at 21:00, } \\
\text { 0: otherwise }\end{array}$ \\
\hline $\begin{array}{c}\text { South Route } \\
\text { (Beginning) }\end{array}$ & $\begin{array}{c}\text { Dummy variable=1: If took the southern } \\
\text { route from the beginning, 0: otherwise }\end{array}$ \\
\hline $\begin{array}{c}\text { North Route } \\
\text { (Beginning) }\end{array}$ & $\begin{array}{c}\text { Dummy variable=1: If took the northern } \\
\text { route from the beginning, 0: otherwise }\end{array}$ \\
\hline
\end{tabular}

Table 7 Travel Time Model of Taxi Probe Data

\begin{tabular}{|c|c|c|c|}
\hline \multirow{2}{*}{$\begin{array}{c}\text { Explanatory Varia- } \\
\text { ble }\end{array}$} & Model 4 & Model 5 & Model 6 \\
\hline & $\begin{array}{c}\text { Estimate } \\
\text { (t-stat) }\end{array}$ & $\begin{array}{c}\text { Estimate } \\
\text { (t-stat) }\end{array}$ & $\begin{array}{c}\text { Estimate } \\
\text { (t-stat) }\end{array}$ \\
\hline Intercept & $\begin{array}{c}228 \\
(14.73 * * * \\
)\end{array}$ & $\begin{array}{c}271.94 \\
\left(14.08^{* * *}\right)\end{array}$ & $\begin{array}{c}167.65 \\
(8.02 * * *)\end{array}$ \\
\hline U-turn & $\begin{array}{c}65.55 \\
\left(3.26^{* * *}\right)\end{array}$ & $\begin{array}{c}61.19 \\
\left(2.16^{* *}\right)\end{array}$ & \\
\hline $\begin{array}{c}\text { Time before Initial } \\
\text { detour }\end{array}$ & - & - & $\begin{array}{c}0.49 \\
(2.14 * *) \\
\end{array}$ \\
\hline Passing Kasugai IC & $\begin{array}{c}46.01 \\
(2.27 * *) \\
\end{array}$ & - & - \\
\hline Number of detours & - & - & $\begin{array}{c}19.63 \\
(4.19 * * *) \\
\end{array}$ \\
\hline $\begin{array}{l}\text { Expressway till Ko- } \\
\text { maki }\end{array}$ & - & $\begin{array}{l}-102.89 \\
(-1.78 *)\end{array}$ & - \\
\hline $\begin{array}{c}\text { Expressway till } \\
\text { Oomori }\end{array}$ & $\begin{array}{c}-66.81 \\
(-3.10 * * *)\end{array}$ & $\begin{array}{c}-74.28 \\
(-2.53 * *)\end{array}$ & $\begin{array}{c}-52.8 \\
(-1.90 *) \\
\end{array}$ \\
\hline Departure_21:00 & $\begin{array}{c}-106.34 \\
(-3.70 * * *)\end{array}$ & & - \\
\hline $\begin{array}{l}\text { South Route (Begin- } \\
\text { ning) }\end{array}$ & - & $\begin{array}{c}-72.5 \\
(-2.34 * *)\end{array}$ & - \\
\hline $\begin{array}{l}\text { North Route dummy } \\
\text { (Beginning) }\end{array}$ & - & $\begin{array}{c}-100.33 \\
(-2.36 * *) \\
\end{array}$ & - \\
\hline $\mathbf{R}^{2}$ & 0.791 & 0.6391 & 0.6348 \\
\hline Samples & 24 & 24 & 24 \\
\hline
\end{tabular}

Note: $* * * * *, *$ indicate that the variables are significant at $1 \%$ significance level, $5 \%$ significance level, and $10 \%$ significance level, respectively.

In Model 4, drivers who avoided flood at Shonai River using expressway and exited at Oomori IC to enter Kasugai could save approximately $66 \mathrm{~min}$. However, drivers who exited from Tomei expressway to Route 19 at Kasugai IC and those who did not use the interchange but the adjacent roads spent an additional $46 \mathrm{~min}$. Some respondents explained that this was because of the closure at Tomei expressway between Kasugai IC and Nagoya IC at around 15:00. 
This forced the traffic on the expressway toward the southern direction from the closure section to exit at Kasugai IC.

From the probe data, we found that the average travel speed of the surrounding roads around Kasugai IC was only $5 \mathrm{~km} / \mathrm{h}$ and this area was heavily congested. This situation showed that closing a section of expressway created a very heavy burden to normal roads in the surrounding.

On the other hand, Oomori IC whereby many drivers used for detour. There was no any traffic regulation imposed at this expressway section, and hence, severe traffic congestion was not found in this area. Next, the U-turn dummy shows that an approximately $60 \mathrm{~min}$ was additionally required for making a round trip due to the U-turns at Points $\mathrm{X}$ and Y. Generally, taxis are always assumed to be well aware of traffic information about the road closures and traffic condition; however, some respondents stated some taxis unexpectedly did not obtain the traffic information. Moreover, some respondents who regularly used cars also mentioned that although they could obtain some information on the traffic regulations from the navigation system, but the actual situation was unclear and kept changing unless they reached to the location. Also, some drivers travelled to the closure location, were stuck, and had to make a U-turn, even when they had noticed the road closure in advance. This was because, at the location much prior to the closure section, the traffic was still moving slowly due to the U-turn control and had caused some drivers to misunderstand that they still could drive pass through the closure section. Departure at 21:00 required less travel time because the traffic volume became lower and the traffic regulation information was obtained accurately.

Model 5 shows that taking a detour route of South or North from the beginning saved more than 72 and 100 mins respectively comparing to using Route 19. Thus, without a U-turn, travelling along Route 19 caused a very long delay. Drivers who travelled on Route 19 and later used the sideway between mountains had encountered very severe congestion than using other routes.

Model 6 considers the time spent until making the initial detour and the total number of detours in the entire travel trajectory. The model shows that about half of the entire travel time was spent as an additional before making the initial detour. Next, approximately $20 \mathrm{~min}$ was additionally required at every detour.

So far, the actual travel conditions in the congestion and road closure areas have been assessed using the travel trajectories of the probe vehicles. We have found several important factors influenced the travel time under the disaster, taking into account of the respondents' opinions in the questionnaires. As a result, especially when enforcing a U-turn control before a road closure section, it is necessary to consider a method to communicate with drivers to consider another detour route and avoid entering into the closure area if possible. With today technology, it is not too difficult to add more information regarding the real-time traffic condition into the car navigation system such as the locations of road closure and U-turn control. Considering the traffic condition, the navigation system should be able to suggest drivers before departure a set of possible detour routes to avoid the bottlenecks with the amount of possible time saving and additional travel distance. Moreover, to reduce the impact on normal roads when closing an expressway section, a measure such as providing an alternative route far in advance or a U-turn within the expressway in front of the closing section for the vehicles traveling to other destinations on the expressway so that they can avoid being forced to exit at the congested IC and to add the extra burden to traffic congestion on normal roads in the surrounding area.

Unexpectedly, this study found that not a few numbers of drivers gathered inaccurate or inadequate traffic information and encountered a very long delay. From the respondents' opinions in the questionnaires, the current navigation system provided only little information on the traffic condition. Drivers could not understand the actual condition until encountering into the congestion locations themselves. Therefore, in order to provide accurate and comprehensive traffic information, some details should be provided during an emergency, such as the locations of the imposed traffic regulations (eg. the U-turn locations and road closures), a more detailed congestion level depicted on the map (eg. distinguishing a severe traffic congestion of a very low travel speed of $1-2 \mathrm{~km} / \mathrm{h}$ from others), suggested detour information especially on expressway, and other relevant information.

On the other hand, according to the travel trajectories of the taxi probes, the taxis had to change their routes at several locations. This situation showed us the difficulty to gather accurate information during a disaster. This might because, when the precipitation rate is more than $30-40 \mathrm{~mm} / \mathrm{h}$, there is a high possibility that roads may be closed due to landslide and inundation at anytime and anyplace. The traffic situation may worsen rapidly from the condition before the departure under such precipitation.

In this study, the questionnaire survey was conducted with the primary focus on the drivers' cir- 
cumstances during the massive downpour. At the analysis stage, we found that unreliable information was a significant factor to increase the difficulty during returning home. However, the responses regarding the traffic information was rather few in this survey. In the future survey, we should pay more attention to the reliability of traffic information. Regarding the probe data, taxis are the probe vehicles in this study. Generally, it is rather uncommon for commuters to travel in a long distance by taxi, therefore, we found only a few trips that travelled in a long distance. Thus, the amount of data was rather few for the analysis of regional impact. In fact, the GPS data of general vehicles can provide a more reliable analysis result with a more number of samples. However, although this time the amount of taxi probe data was rather few, the data provided not too less information to understand the actual circumstances the drivers facing during the typhoon and hinted some important factors for the analysis of questionnaire survey.

\section{CONCLUSION}

In this study, taxi probe and a questionnaire survey on the returning home behavior of commuters during the 2011 Typhoon Roke were analyzed. Firstly, many closure locations were found at expressways and arterial roads in Aichi and Gifu prefectures due to the typhoon, especially the roads towards the northeastern direction from Central Nagoya including Kasugai and Tajimi.

From the questionnaire analysis, considering the distribution of the differences between the departure time on the day of disaster and on a regular basis, the findings revealed that commuters started to depart from when the initial information on the flood damage was reported, until about $2 \mathrm{~h}$ later than their regular departure time. However, the regression analysis showed that commuters who departed earlier than usual had faced a significant delay since the road closures started to be enforced.

In addition, we found that respondents who gathered the traffic information before their departure travelled faster than ones who did not, although the consequence of acquiring inaccurate information was not so small.

From a more detailed analysis of the probe data in Kasugai-Tajimi area, we found that many probe cars towards Tajimi took several detours and U-turns and resulted in a very long travel delay. Thus, several countermeasures to reduce the chaos around the road closure points and the closed ICs on expressway were proposed. Besides, according to the respond-
F3 (Civil Engineering Informatics), Vol. 72, No. 2, I_1-I_13, 2016.

ents' opinions, the accurate and comprehensive traffic information should be provided during an emergency, such as the locations of the imposed traffic regulations and a more detailed congestion level depicted on the map. However, the traffic situation kept changing under a very high precipitation. Thus, in the future disaster, drivers are suggested to wait at their office during the precipitation of more than $30-40 \mathrm{~mm} / \mathrm{h}$ and until the reliable and accurate traffic information can be obtained.

In the future studies, we look forward to develop a traffic simulation in order to examine the effect of suggested countermeasures and the rate of improvement of the congestion situation. In addition, the questionnaire responses also indicated that there was significant amount of traffic for picking up commuters from the train stations along Tajimi rail line (such as Inuyama, Shinryo, Kozoji stations, and so on). Therefore, it is necessary to analyze these behaviors to estimate this additional traffic volume and its effect on the drivers' behavior in the future.

\section{REFERENCES}

1) Imakita, E. : Issues on Non-Life Insurance, Presentation at Workshop on Using Meteorological Information for Industry Advancement, 2014.

2) Giuliano, G. and Golob, J. : Impacts of the Northridge Earthquake on Transit and Highway Use, Journal of Transportation and Statistics, pp. 2-20, 1998.

3) Report on the Meeting for Countermeasures on Commuter Strand Problems in an Earthquake Aftermath in Tokyo, 2012

4) Hiroi, Y., Sekiya, N., Nakajima, R., Waragai, S. and Hanahara, H. : Questionnaire Survey concerning Stranded Commuters in Metropolitan Area in the East Japan Great Earthquake, Journal of Institute of social safety science, Vol. 15, pp. 343-353, 2011.

5) Fujiu, M., Numada, M., Takada, K., Matsubara, T., Ohara, M. and Meguro, K. : Characteristics of commuters' behavior Under The 2011 off the Pacific coast of Tohoku Earthquake, Journal of JAEE, Vol. 12, No. 4 (Special Issue), pp. 177-188, 2012.

6) Ito, K., Aono, S. and Ohmori, N. : Empirical Study on Stop-offs en Route Home in the Aftermath of an Earthquake Disaster in the Tokyo Metropolitan Area - Analyses Based on an Online Questionnaire Survey about the Great East Japan Earthquake - , Journal of the City Planning Institute of Japan, Vol. 48, No. 3, pp. 873-878, 2013.

7) Koyama, M. and Okada, S. : Stochastic Estimation and Questionnaire Survey on Stranded Commuters in Nagoya City, Journal of Social Safety Science, No. 13, pp. 243-253, 2010.

8) Mitamura, J., Fujita, M., Suzuki, K. and Kagami, S. : Analysis on Travel Activity for Mainly Public Transport Users Returning Home under Downpour, Journal of Japan Society of Civil Engineers, Vol. 25, No. 4, pp. 997-1008, 2008.

9) Sakamoto, J., Fujita, M., Suzuki, K. and Yamamoto, K. : An Analysis of Effective Information and Travel Activity Returning Home by Car under Downpour, Journal of Infrastructure Planning Review, Vol. 24, No. 4, pp. 861-868, 2007. 
10) Liang, Z., Jian-Min, X., Lian-Xian, Z. : Arterial Speed Studies with Taxi Equipped with Global Positioning Receivers as Probe Vehicle, International Conference of IEEE, Vol. 2, pp. 1343-1347, 2005.

11) Khan, M. H. M., Wisetjindawat, W., Fujita, M. and Suzuki, K. : An Analysis of Probe Data on Traffic Congestion During the Typhoon Using GIS Application, Proc. of the Eastern Asia Society for Transportation Studies, Vol.9, 2013.

(Received October 14, 2016) 